\title{
Lack of significant skin inflammation during elimination by apoptosis of large numbers of mouse cutaneous mast cells after cessation of treatment with stem cell factor
}

\author{
Marcus Maurer ${ }^{1}$ and Stephen J Galli ${ }^{2}$ \\ ${ }^{1}$ Department of Dermatology and Allergy, University Hospital Charité Berlin, Germany and ${ }^{2}$ Department of \\ Pathology, Stanford University Medical Center, Palo Alto, CA, USA
}

\begin{abstract}
We previously reported that subcutaneous (s.c.) administration of stem cell factor (SCF), the ligand for the c-Kit receptor, to the back skin of mice promotes marked local increases in the numbers of cutaneous mast cells (MCs), and that cessation of SCF treatment results in the rapid reduction of cutaneous MC populations by apoptosis. In the present study, we used the ${ }^{125}$-fibrin deposition assay, a very sensitive method for quantifying increased vascular permeability, to assess whether the clearance of large numbers of apoptotic MCs is associated with significant cutaneous inflammation. The s.c. injection of $\operatorname{rrSCF}^{164}(30$ or $100 \mu \mathrm{g} / \mathrm{kg} / \mathrm{day})$ or rrSCF $^{164}$-peg (polyethylene glycol-treated SCF, 30 or $100 \mu \mathrm{g} / \mathrm{kg} /$ day) for 23 days increased the numbers of dermal MCs at skin injection sites from $5.1 \pm 0.7 \mathrm{MCs} / \mathrm{mm}^{2}$ to $36.4 \pm 4.1,34.7 \pm 9.7,52.5 \pm 5.8$, and $545 \pm 97 \mathrm{MCs} /$ $\mathrm{mm}^{2}$, respectively. In contrast, MC numbers were markedly lower in mice that had been treated with SCF for 21 days, followed by 2 days of injection with the vehicle alone. Notably, when tested during the period of rapid reduction of skin $\mathrm{MCs},{ }^{125}$-fibrin deposition in the skin was very similar to that in mice receiving continuous treatment with SCF or vehicle. We conclude that the rapid elimination of even very large populations of MCs by apoptosis, which also results in the clearance of the considerable quantities of proinflammatory products stored by these cells, does not lead to significant local cutaneous inflammatory responses.

Laboratory Investigation (2004) 84, 1593-1602, advance online publication, 25 October 2004; doi:10.1038/labinvest.3700196
\end{abstract}

Keywords: apoptosis; c-Kit; inflammation; mast cells; stem cell factor; skin

It is widely believed that apoptosis, or programmed cell death, can result in the elimination of cell populations without inducing an associated inflammatory response. ${ }^{1-3}$ Yet few studies have actually tested this hypothesis by using sensitive methods to search for, and to quantify, evidence of local inflammation in tissues that include large populations of cells that are undergoing apoptosis.

Therefore, we searched for evidence of inflammation at cutaneous sites that contained greatly expanded populations of dermal mast cells (MCs) that were undergoing apoptosis after the withdrawal of treatment with recombinant rat stem cell factor (rrSCF).$^{4}$ We selected this model for three reasons. First, MCs are arguably among the most 'proinflam-

Correspondence: Dr SJ Galli, MD, Department of Pathology, Lane Building, L-235, Stanford University School of Medicine, 300 Pasteur Drive, Stanford, CA 94305-5324, USA.

E-mail: sgalli@stanford.edu

Received 29 June 2004; revised 13 September 2004; accepted 14 September 2004; published online 25 October 2004 matory' of the cell types that might be examined to assess the potential effects of apoptosis on the induction of tissue inflammation. In addition to being able to synthesize potent proinflammatory lipid mediators and cytokines upon appropriate activation, MCs contain preformed stores of biogenic amines (histamine, and, in mice and rats, serotonin) and other inflammatory mediators in their prominent cytoplasmic granules. ${ }^{5,6}$ Accordingly, it is thought that agents that induce MC injury or necrosis can cause the local development of an inflammatory response in parallel with the release of MC cytoplasmic granule contents to the interstitial space. ${ }^{5,6}$ Indeed, inflammation can also be induced by the intracutaneous injection of cytoplasmic granules that have been purified from MCs. ${ }^{7}$

Second, we previously reported that the repetitive subcutaneous (s.c.) injection of mice with polyethylene glycol-modified rrSCF resulted in a marked expansion of tissue MC populations, ${ }^{4,8}$ and that the numbers of dermal MCs in cutaneous sites injected with rrSCF rapidly diminished after cessation of 
rrSCF treatment. ${ }^{4,8}$ Both studies of the effects of stem cell factor (SCF) on mouse MC apoptosis in vitro, ${ }^{4}$ which assessed MC apoptosis both by morphology and by detection of the characteristic pattern of DNA fragmentation associated with apoptosis, and our histological examination of the sites of repetitive s.c. rrSCF injection in vivo, ${ }^{4}$ which documented the presence of apoptotic MCs (as well as occasional adjacent eosinophils or macrophages) in sections obtained 24 or $36 \mathrm{~h}$ after stopping SCF treatment, indicated that the rapid fall in dermal MC numbers, which occurred upon cessation of rrSCF treatment in vivo, reflected the apoptosis of such MCs. These studies thus established an in vivo model system that can be used to examine the extent to which the massive loss of dermal MC populations via apoptosis might result in the induction of a cutaneous inflammatory response.

Third, several studies indicate that the extravasation of intravenously administered ${ }^{125}$ I-fibrinogen, as well as the local interstitial deposition of crosslinked ${ }^{125}$ I-fibrin, represents an extremely sensitive method for detecting and quantifying the enhanced vascular permeability that is associated with inflammatory responses elicited in mouse skin. ${ }^{9-13}$ Such responses include cutaneous contact hypersensitivity reactions, ${ }^{9}$ IgE-dependent passive cutaneous anaphylaxis responses ${ }^{10}$ and reactions to the intradermal injection of substance $\mathrm{P}^{11}$ or $\mathrm{SCF}^{12}$ or the epicutaneous application of PMA. ${ }^{13}$ For example, in tests of cutaneous contact hypersensitivity reactions, the ${ }^{125}$ I-fibrin deposition assay was more sensitive than standard measurements of tissue swelling in detecting weak responses. ${ }^{9}$

In the present study, we assessed the local extravasation of ${ }^{125}$ I-fibrinogen and deposition of crosslinked ${ }^{125}$ I-fibrin, and performed histological analysis, to search for evidence of cutaneous inflammation at sites in which dermal MC numbers were dropping dramatically after cessation of treatment with rrSCF. The results strongly support the conclusion that even greatly expanded populations of mouse MCs can be eliminated by apoptosis in the virtual absence of any induction of a significant local inflammatory response.

\section{Materials and methods}

\section{Animals}

C57BL/6 mice (male, 6-8 weeks old at the beginning of the experiments) were purchased from Jackson Laboratories (Bar Harbor, ME, USA). Mice were kept in community cages at the Beth Israel Deaconess Medical Center Animal Care Facilities at light periods of $12 \mathrm{~h}$ and were fed water and mouse chow ad libitum. All animal experiments were conducted in accordance with the guidelines of the NIH and the Beth Israel Deaconess Medical Center Institutional Animal Care and Use Committee.

\section{Elicitation of MC Apoptosis}

To induce increased numbers of cutaneous MC populations, mice received for either 3 weeks or 3 months daily s.c. injections (always to the same flank site) of vehicle alone, Escherichia coli-derived $\operatorname{rrSCF}^{164}$ or $\operatorname{rrSCF}^{164}$, which had been modified by the covalent attachment of polyethylene glycol (ie, rrSCF ${ }^{164}$-peg), to increase the biological half-life of the cytokine, at 30 or $100 \mu \mathrm{g} / \mathrm{kg}$ in $150-250 \mu \mathrm{l}$ of vehicle (vehicle $=$ sterile saline containing $0.1 \%$ bovine serum albumin (fraction $\mathrm{V}$, fatty acid free: ICN Immunobiologicals, Lisle, Il, USA)). To assess the effects of a rapid reduction of MC numbers, in some mice (the 'SCF withdrawal' group), the injections with $\operatorname{rrSCF}^{164}$ or $\mathrm{rrSCF}^{164}$-peg were then stopped and these mice received subsequent s.c. injections of vehicle (into the same sites used for rrSCF or rrSCF-peg treatment) at $\sim 6$ and $30 \mathrm{~h}$ before the mice were killed (see below). Other mice continued to receive injections of rrSCF or rrSCFpeg (the 'SCF continued' group) or of vehicle alone. In some experiments, skin histamine content was determined using a Histamine Enzyme Immunoassay Kit (Immunotech, Miami, FL, USA) according to the manufacturer's instructions.

\section{Induction of Cutaneous Reactions to Histamine or IgE and Antigen}

In some experiments, cutaneous sites in mice in the SCF or vehicle treatment groups were injected intradermally with histamine $(2 \mu \mathrm{g}$ in $20 \mu \mathrm{l}$ of vehicle) or vehicle (sterile saline, $20 \mu \mathrm{l}$ ) alone. In other studies, cutaneous sites in mice in the SCF or vehicle treatment groups were injected intradermally with a mouse monoclonal IgE with specificity for $\mathrm{DNP}^{14}$ at $100 \mathrm{ng}$ in $20 \mu \mathrm{l}$ of vehicle or $20 \mu \mathrm{l}$ vehicle alone, and the mice were injected approximately $24 \mathrm{~h}$ later intravenously with $200 \mu \mathrm{g}$ of DNPHSA in $100 \mu \mathrm{l}$ of vehicle to induce IgE-dependent passive cutaneous anaphylaxis reactions.

\section{Assessment of Skin Inflammation by Measurement of ${ }^{125}$ I-fibrinogen Extravasation and ${ }^{125} \mathrm{I}$-fibrin Deposition}

At $4 \mathrm{~h}$ before they were killed (eg, in the SCF withdrawal group, 50 hours after the cessation of SCF treatment), mice were injected i.v. with $3 \times 10^{6}$ counts per minute (cpm) of ${ }^{125}$ I-guinea-pig fibrinogen. After the mice were killed by cervical dislocation, ${ }^{125}$ I-fibrinogen extravasation and ${ }^{125}$ I-fibrin deposition were assessed as previously described. ${ }^{9}$ Briefly, mice received i.v. injections with a mixture of antifibrinolytic agents and anticoagulants to impede additional clotting or fibrinolysis during specimen preparation. Each mouse received $0.2 \mathrm{ml}$ of a mixture containing $80 \mathrm{U}$ heparin, $20 \mathrm{mg}$ D-phenylalanyl-L-prolyl-L-arginine chloromethyl ketone (P-PAC), $2 \mathrm{mg}$-aminocaproic acid (EACA), 
and $56 \mathrm{U}$ Trasylol, all in $0.15 \mathrm{M}$ sterile $\mathrm{NaCl}$. Immediately thereafter, mice were anesthetized with ether, and a sample of retro-orbital blood was obtained. These samples, which exhibited no clotting during an observation period of $3 \mathrm{~h}$, were centrifuged at $10000 \mathrm{~g}$ at room temperature to prepare plasma for radioactive counting. One 6mm punch biopsy from the skin injection site and a skin control site and half the spleen were minced into fine fragments in $2 \mathrm{ml} 0.01 \mathrm{M}$ phosphate buffer (pH 7.5) containing a mixture of proteolytic inhibitors: heparin $(10 \mathrm{U} / \mathrm{ml})$, P-PAC $(5 \mathrm{mg} / \mathrm{ml})$, EDTA ( $2 \mathrm{mg} / \mathrm{ml})$, EACA (0.1 M), Trasylol (10 U/ml), $2 \mathrm{mM}$ phenylmethylsulfonic flouride, $2 \mathrm{mM}$ iodoacetate and $2 \mathrm{mM} N$-ethylmaleimide. The minced tissues were then extracted in the buffer by keeping the tubes for $18 \mathrm{~h}$ at $4^{\circ} \mathrm{C}$. Each tube was centrifuged $\left(1000 \mathrm{~g}\right.$ for $20 \mathrm{~min}$ at $20^{\circ} \mathrm{C}$ ), and the supernatant decanted. The pellet containing the tissue fragments was resuspended vigorously in $2 \mathrm{ml}$ of the same buffer and was centrifuged again as described before. The supernatant was aspirated and was pooled with the earlier extract for radioactive counting as the aqueous extract. The centrifuged tissue fragments were then resuspended in $2 \mathrm{ml}$ freshly prepared $3 \mathrm{M}$ urea, extracted for $2 \mathrm{~h}$ at $37^{\circ} \mathrm{C}$, centrifuged $\left(1000 \mathrm{~g}\right.$ for $20 \mathrm{~min}$ at $20^{\circ} \mathrm{C}$ ), and the urea-soluble supernatant and the urea-insoluble pellet were counted for radioactivity in a gamma counter.

\section{Histologic Studies}

Specimens from the biopsies taken from the skin injection sites and from the contralateral control sites (which had received no injections), and specimens from the spleens, were transfered to Karnovsky's fixative $2 \%$ paraformaldehyde, $2.5 \%$. glutaraldehyde, $0.025 \% \mathrm{CaCl}_{2}$ in $0.1 \mathrm{M}$ cacodylate buffer, pH 7.4, for $12 \mathrm{~h}$ at $4{ }^{\circ} \mathrm{C}$ ) or Carnoy's fixative (60\% ethanol, $30 \%$ chloroform, $10 \%$ acetic acid, for $4 \mathrm{~h}$ at $4^{\circ} \mathrm{C}$ ). The presence of tissue MCs was assessed in $1 \mu \mathrm{m}$, Epon-embedded, Giemsa-stained sections as previously described. ${ }^{13}$ Briefly, sections were coded so that the observer was not aware of the identity of individual specimens and examined at $\times 1000$ by light microscopy to quantify $\mathrm{MCs} / \mathrm{mm}^{2}$ of dermis or spleen parenchyma.

\section{Statistical Analysis}

The data were analyzed for statistical significance using the unpaired two-tailed Student's $t$-test to compare values derived from mice from the various treatment groups, and using the paired two-tailed Student's $t$-test to compare values from skin injection and contralateral control sites of the individual mice.

\section{Results}

S.c. Injections with $\operatorname{rrSCF}^{164}$ or $\operatorname{rrSCF}^{164}$-peg Result in Increased Numbers of Cutaneous and Spleen MCs and Cessation of Treatment with $\mathrm{rrSCF}^{164}$-peg Induces Rapid Reductions of Skin MC Populations

In confirmation of our previous studies employing $\mathrm{WCB} \mathrm{F}_{1}$ mice, ${ }^{4,8}$ we found that the chronic treatment of C57BL/6 mice with daily s.c. injections of polyethylene glycol-treated $\operatorname{rrSCF}^{164}$ ( $\mathrm{rSCF}^{164}$-peg) for 23 days resulted in increased numbers of MCs at the site of injection, in untreated control skin and the spleen (Figures 1c, f and 2).

We also assessed whether $\operatorname{rSCF}^{164}$ that had not been treated with polyethylene glycol also can induce increased MC numbers and whether prolonged treatment with $\mathrm{rrSCF}^{164}$-peg for 92 days can further enhance the increase in MC numbers over that observed after a 23-day treatment period. Figure 2 shows that injections of $\operatorname{rrSCF}^{164}$ at 30 or $100 \mu \mathrm{g} / \mathrm{kg} /$ day also resulted in increased MCs at the site of injection and a contralateral skin control site as compared to continued injections with vehicle. When $\mathrm{rrSCF}^{164}$-peg $(100 \mu \mathrm{g} / \mathrm{kg} /$ day $)$ was injected daily for 92 days, MC numbers increased markedly as compared to that observed with continued injection of vehicle. However, only the increase of MC numbers in the spleen was enhanced as compared to that observed after a 23-day treatment period with the same dose of rSCCF$^{164}$-peg (Figure 2).

When injections of $\mathrm{rrSCF}^{164}$ or $\mathrm{rrSCF}^{164}$-peg were discontinued for $54 \mathrm{~h}, \mathrm{MC}$ numbers in the skin at the injection sites were significantly lower (by $>50 \%$ ) in mice that had been treated with $\mathrm{rrSCF}^{164}$-peg at $100 \mu \mathrm{g} / \mathrm{kg} /$ day for 21 or 90 days (reductions of $\sim 356$ or $\sim 205 \mathrm{MC} / \mathrm{mm}^{2}$, respectively) and in mice that had been treated with $\mathrm{rrSCF}^{164}$ at $30 \mu \mathrm{g} / \mathrm{kg} /$ day for 21 days (a reduction of $\sim 23 \mathrm{MC} / \mathrm{mm}^{2}$ ), as compared to mice that received continued injections with SCF (ie, for a total of 23 or 92 days) (Figures $1 \mathrm{~b}$, e and 2). In these groups, reductions of MC numbers upon cessation of $\mathrm{rrSCF}^{164}$-peg treatment also occurred in the skin control sites that had not been directly injected with rrSCF ${ }^{164}$-peg (reductions of $\sim 32$ or 20 $\mathrm{MC} / \mathrm{mm}^{2}$ for mice treated with $100 \mu \mathrm{g} / \mathrm{kg} /$ day for 21 or 90 days, respectively) or $\operatorname{rrSCF}^{164}$ (a reduction of $\sim 11 \mathrm{MC} / \mathrm{mm}^{2}$ for mice treated with $30 \mu \mathrm{g} / \mathrm{kg} /$ day) but not in the spleens. By contrast, a $54 \mathrm{~h}$ cessation of SCF treatment did not result in significant reductions in $\mathrm{MC}$ numbers in the skin of mice treated with $\mathrm{rrSCF}^{164}$ at $100 \mu \mathrm{g} / \mathrm{kg} /$ day or $\mathrm{rrSCF}^{164}$ peg at $30 \mu \mathrm{g} / \mathrm{kg} /$ day for 21 days, compared to the corresponding values in mice that received continued treatment with SCF for 23 days (Figure 2). Accordingly, we used mice treated with $\mathrm{rSCF}^{164}$ peg at $100 \mu \mathrm{g} / \mathrm{kg} /$ day for the majority of the other studies reported herein.

We also determined whether the increase of skin MCs after chronic treatment with SCF was associated with an increase of tissue histamine content 

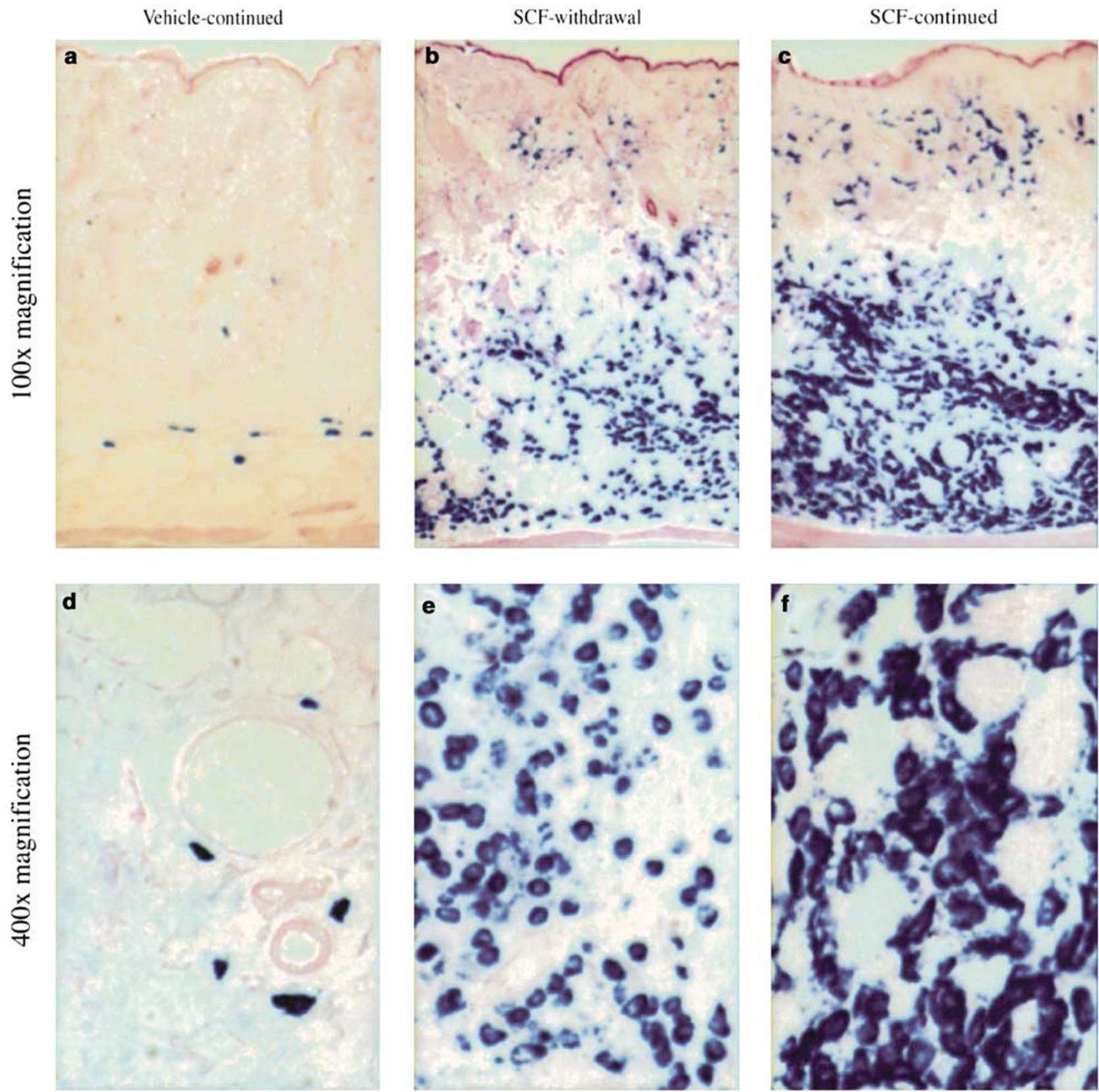

Figure 1 S.c. injection with $\mathrm{rrSCF}^{164}$-peg at $100 \mu \mathrm{g} / \mathrm{kg} /$ day for 23 days results in increased numbers of cutaneous MCs and cessation of treatment on day 21 induces rapid reductions of skin mast cell populations. Alcian Blue staining of skin sections at injection sites of $\mathrm{rrSCF}^{164}$-peg $(100 \mu \mathrm{g} / \mathrm{kg} /$ day $)$ or vehicle demonstrates markedly increased numbers of dermal MCs after 23 days of injection with rrSCF $^{164}$-peg (c $+\mathbf{f}$; 'SCF-continued') as compared to skin of mice treated only with vehicle (a+d; 'vehicle-continued'). When SCFinjections were discontinued after 21 days, MC numbers dropped rapidly within the next $54 \mathrm{~h}(\mathbf{b}+\mathbf{e}$; 'SCF withdrawal'). $\mathbf{a}-\mathbf{c}=\times 100$ magnification, $\mathbf{d}-\mathbf{f}=\times 400$ magnification; 4- $\mu \mathrm{m}$ paraffin-embedded, Alcian blue-stained sections with eosin counterstain.

and whether the reduction of MCs after cessation of SCF injections was paralleled by a decrease of histamine levels. We examined skin histamine content at the site of daily injections with $\mathrm{rrSCF}^{164}$-peg (100 $\mu \mathrm{g} / \mathrm{kg} /$ day) for 21 days at $54 \mathrm{~h}$ after discontinuation of SCF injections ('SCF withdrawal' group) or after continued injections with SCF, for a total of 23 days ( 'SCF continued' group) (Figure 3). In mice that received $\mathrm{rrSCF}^{164}$-peg for a total of 23 days, skin histamine levels at the site of injection and untreated control skin were markedly increased as compared to values in vehicle-treated mice. When SCF injections were stopped after 21 days, the skin histamine content at the site of injection and at the control site dropped rapidly and significantly (by $>50 \%$ ) within the next $54 \mathrm{~h}$ (Figure 3). The reductions in skin histamine content and numbers of cutaneous MCs upon cessation of 

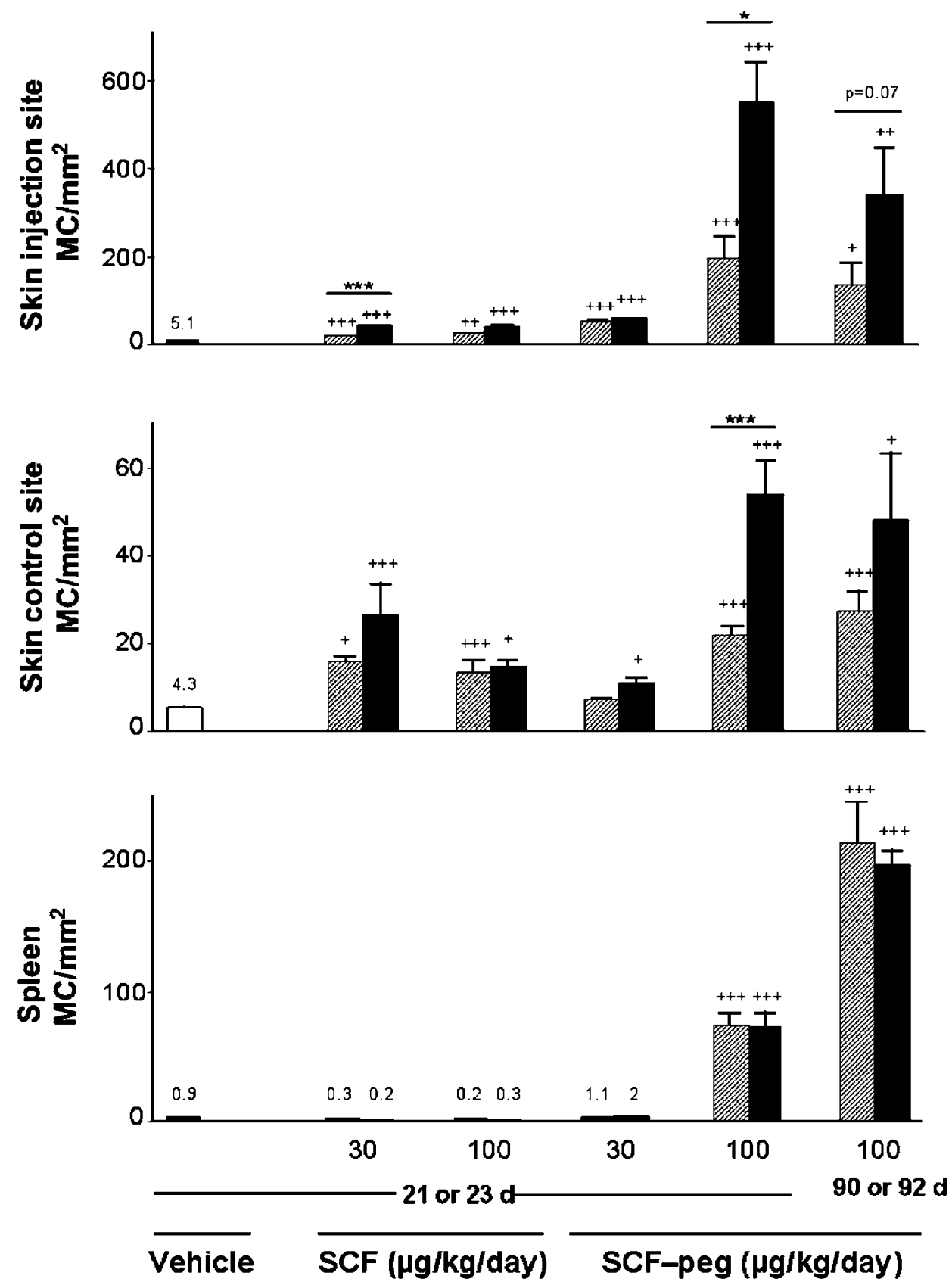

\section{$\square$ Vehicle $\quad$ SCF withdrawal SCF continued}

Figure 2 Numbers of cutaneous and spleen MCs in mice treated with various amounts of rrSCF ${ }^{164}$ or rrSCF ${ }^{164}$-peg. Numbers of MCs in the dermis at the skin injection site or contralateral control skin site or spleen, of C57BL/6 mice that had been injected with vehicle, rrSCF $^{164}$ (30 or $100 \mu \mathrm{g} / \mathrm{kg} /$ day), or rrSCF $^{164}$-peg (30 or $100 \mu \mathrm{g} / \mathrm{kg} /$ day, s.c., $n=6$ per group). After 21 or 90 days of treatment, injections of SCF were discontinued ('SCF withdrawal') to induce MC apoptosis or continued ('SCF continued') and mice were killed after $54 \mathrm{~h}$ for morphometric quantification of MCs. Bars represent mean + s.e.m. of MC numbers per $\mathrm{mm}^{2}$ of tissue (alkaline Giemsa, $\times 1000$ ); for low values, only mean numbers of MCs are shown. Significant differences $v s$ control ('vehicle continued') mice are shown as ${ }^{+} P<0.05$, ${ }^{+}+P<0.005,+++P<0.001$ (Student's $t$-test for unpaired samples, two-tailed). Significant differences between 'SCF withdrawal' and 'SCF continued' mice in the same SCF dose groups are shown as ${ }^{*} P<0.05$, ${ }^{*} P<0.005,{ }^{* *} P<0.001$ (Student's $t$-test for unpaired samples, two-tailed), as indicated by the comparison bars.

SCF treatment were quite similar in magnitude (cf. results in Figures 2 and 3). These findings confirm that reductions in cutaneous $\mathrm{MC}$ numbers by apoptosis indeed result in parallel reductions of an inflammatory mediator that is stored in the MC granules. 


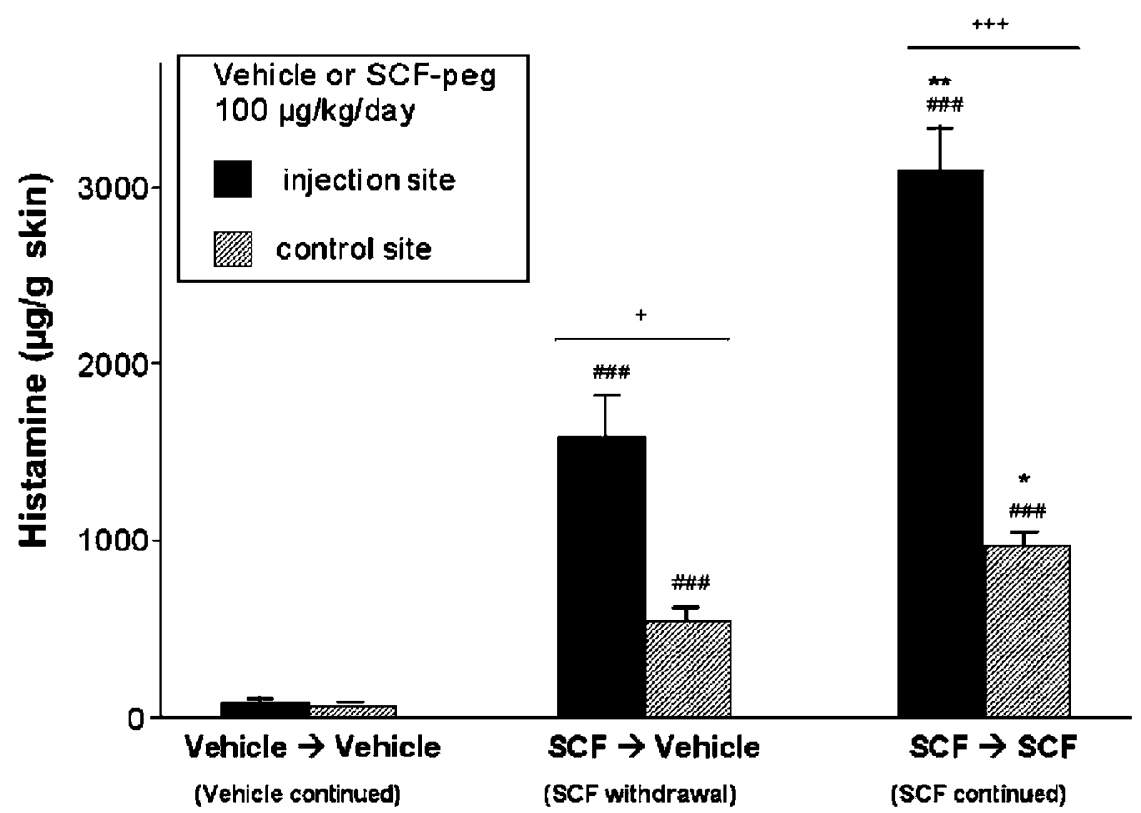

Figure 3 Clearance of apoptotic skin MCs after cessation of chronic treatment with SCF-peg at $100 \mu \mathrm{g} / \mathrm{kg} / \mathrm{day}$ is associated with a reduction of skin histamine content. Changes in histamine content in the skin at SCF or vehicle injection sites and contralateral control skin sites (no injections) of C57BL/6 mice after cessation of chronic treatment with vehicle or $\mathrm{rrSCF}^{164}-\mathrm{peg}(100 \mu \mathrm{g} / \mathrm{kg} / \mathrm{day})$ for $21 \mathrm{days}$ (s.c., $n=4$ per group, to induce MC apoptosis, = 'SCF withdrawal') or after continued injections of vehicle ('vehicle continued') or after daily injections with SCF for 23 days ('SCF continued'). At $24 \mathrm{~h}$ and $48 \mathrm{~h}$ after the last (21st) injection, mice in the SCF withdrawal and Vehicle groups received an injection with vehicle and mice in the SCF continued group received an injection with SCF. At $54 \mathrm{~h}$ after the 21st injection, all mice were killed and a 6-mm punch biopsy was taken from the site of injection and a contralateral control (no injection) site. Biopsies were weighed and histamine was extracted and measured by EIA. Bars represent means + s.e.m. Statistical significance of control (no injection) VS injection sites of animals within individual treatment groups: paired Student's $t$-test, two-tailed $\left({ }^{+} P<0.05\right.$, $\left.{ }^{+++} P<0.005\right)$. Statistical significance of differences between injection or control sites in different treatment groups: unpaired Student's

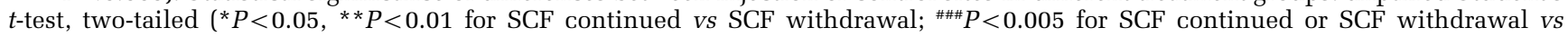
vehicle continued).

Figure 4 Induction of MC apoptosis by cessation of chronic treatment with SCF is not associated with increased vascular permeability. (a) ${ }^{125}$ I-Fibrinogen-derived CPM in biopsies of skin injection sites, contralateral skin control sites (no injections) and spleens of C57BL/6 mice after cessation of chronic treatment with $\operatorname{rrSCF}^{164}$ (30 or $100 \mu \mathrm{g} / \mathrm{kg} /$ day, in two different experiments, for 21 days, s.c., $n=5$ ) to induce MC-apoptosis ('SCF withdrawal') or after continued injections of SCF ('SCF continued'). At 24 and $48 \mathrm{~h}$ after the last (21st) injection with SCF, mice in the SCF withdrawal group received an injection with vehicle and mice in the SCF continued group received an injection with SCF (ie, for a total of 23 days of treatment with SCF). At $50 \mathrm{~h}$ after the 21st injection with SCF, mice in both groups received ${ }^{125}$ I-fibrinogen i.v. and the amount and pattern of extractability of ${ }^{125} \mathrm{I}$-CPM were determined $4 \mathrm{~h}$ later. Numbers in parentheses over the bars = mean value for skin injection site divided by the corresponding value for the control skin site. At the time of killing, the ${ }^{125} \mathrm{I}-\mathrm{CPM}$ in $50 \mu \mathrm{l}$ of serum in the two experiments were as follows: SCF withdrawal $(30 \mu \mathrm{g} / \mathrm{kg}), 35597 \pm 4622$; SCF continued (30 $\left.\mu \mathrm{g} / \mathrm{kg}\right)$, $29752 \pm 2375$; SCF withdrawal $(100 \mu \mathrm{g} / \mathrm{kg}), 19598 \pm 2621$; SCF continued (100 $\mu \mathrm{g} / \mathrm{kg}), 21715 \pm 5157$. (b) ${ }^{125} \mathrm{I}$-Fibrinogen-derived CPM in biopsies of skin injection sites, contralateral skin control sites (no injections) and spleens of C57BL/6 mice after cessation of chronic treatment with $\mathrm{rrSCF}^{164}$-peg ( $30 \mu \mathrm{g} / \mathrm{kg} /$ day for 21 days, s.c., $\left.n=5\right)$ to induce MC-apoptosis ('SCF withdrawal') or after continued injections of SCF ('SCF continued') or after daily injections of vehicle ('vehicle continued'). At 24 and $48 \mathrm{~h}$ after the last (21st) injection with SCF or vehicle, mice in the SCF withdrawal and vehicle continued groups received an injection with vehicle and mice in the SCF continued group received an injection with SCF (ie, for a total of 23 days of treatment with SCF). At $50 \mathrm{~h}$ after the 21 st injection with SCF or vehicle, mice in all groups received ${ }^{125}$ I-fibrinogen i.v. and the amount and pattern of extractability of ${ }^{125} \mathrm{I}$-CPM were determined $4 \mathrm{~h}$ later. Numbers in parentheses over the bars=mean value for skin injection site divided by the corresponding value for the control skin site. Statistical significance of differences of skin injection sites vs control sites in the same treatment groups: paired Student's $t$-test, twotailed $\left({ }^{*} P<0.01,{ }^{* *} P<0.005\right)$. At the time of killing, the ${ }^{125}$ I-CPM in $50 \mu$ l of serum were as follows: SCF withdrawal, 2317 $\pm 173 ;$ SCF continued, $2377 \pm 206$; vehicle continued, $2556 \pm 207$. (c) ${ }^{125}$ I-species in skin injection sites, contralateral skin control sites (no injection) and the spleens of C57BL/6-mice after cessation of chronic treatment with rrSCF ${ }^{164}$-peg (100 $\mu \mathrm{g} / \mathrm{kg} /$ day for 21 or 90 days, s.c., $\left.n=5\right)$ to induce MC apoptosis ('SCF withdrawal') or after continued injections of SCF ('SCF continued'). At 24 and $48 \mathrm{~h}$ after the last (21st or 90 th) injection with SCF, mice in the SCF withdrawal and SCF continued groups received an injection with vehicle or SCF (ie, for a total of 23 or 92 days of treatment with SCF), respectively. At $50 \mathrm{~h}$ after the 21st or 90th injection with SCF, mice in both groups received ${ }^{125} \mathrm{I}-$ fibrinogen i.v. and the amount and pattern of extractability of ${ }^{125} \mathrm{I}-\mathrm{CPM}$ were determined $4 \mathrm{~h}$ later. Numbers in parentheses over the bars = mean value for skin injection site divided by the corresponding value for the control skin site. Statistical significance of differences of skin injection sites vs skin control sites in the same treatment groups: paired Student's $t$-test, two-tailed $\left({ }^{*} P<0.05,{ }^{*} P<0.01\right.$, $* * * P<0.005$ ). For skin injection sites in mice treated with $\mathrm{rrSCF}^{164}$-peg at $100 \mu \mathrm{g} / \mathrm{kg} / \mathrm{day}$ for 21 days, all comparisons for values in the SCF continued vs SCF withdrawal groups are $P \sim 0.07-0.36$. At the time of killing, the ${ }^{125} \mathrm{I}-\mathrm{CPM}$ in $50 \mu \mathrm{l}$ of serum were as follows: SCF withdrawal (21 days of treatment), 2216 \pm 304 ; SCF continued (21 days of treatment), 2162 \pm 294 ; SCF withdrawal (90 days of treatment), $904 \pm 40$; SCF continued (90 days of treatment), $800 \pm 51$ 
Induction of MC apoptosis by Cessation of Chronic Treatment with SCF is not Associated with Increased Vascular Permeability

To assess whether the rapid clearance of markedly increased MC populations after cessation of chronic injections with SCF is associated with increased vascular permeability, the extravasation
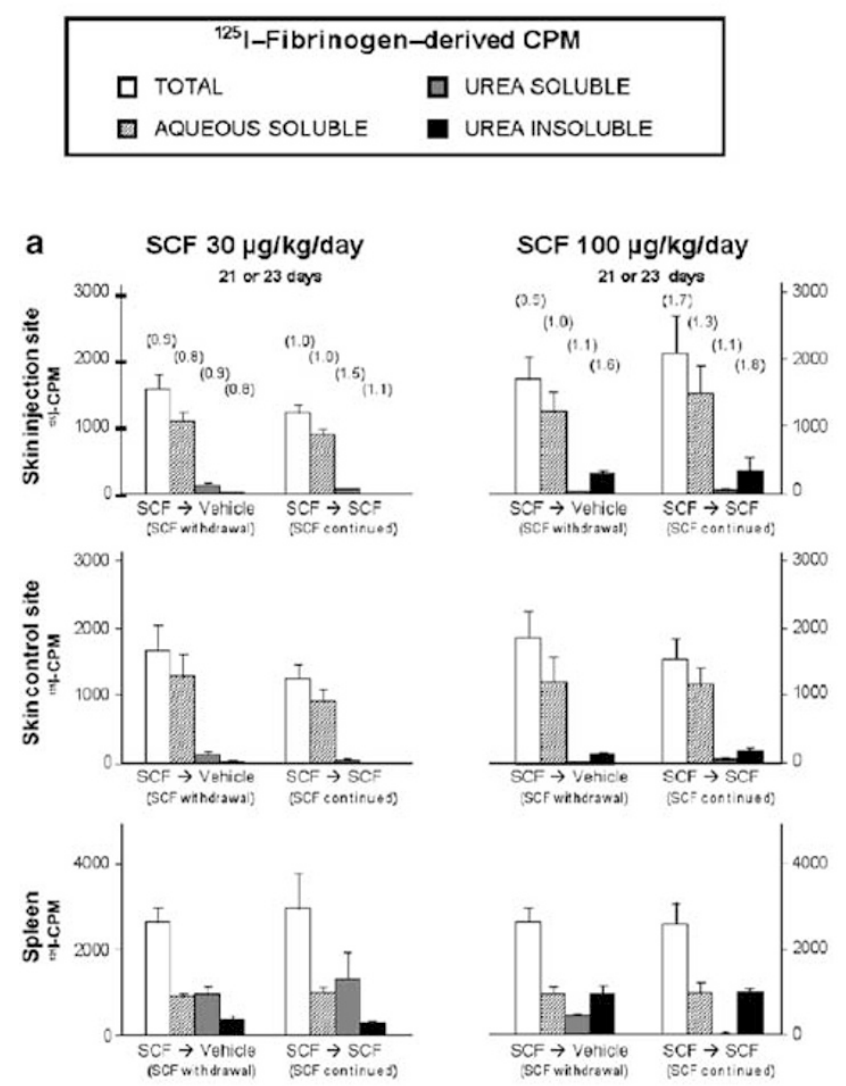

C
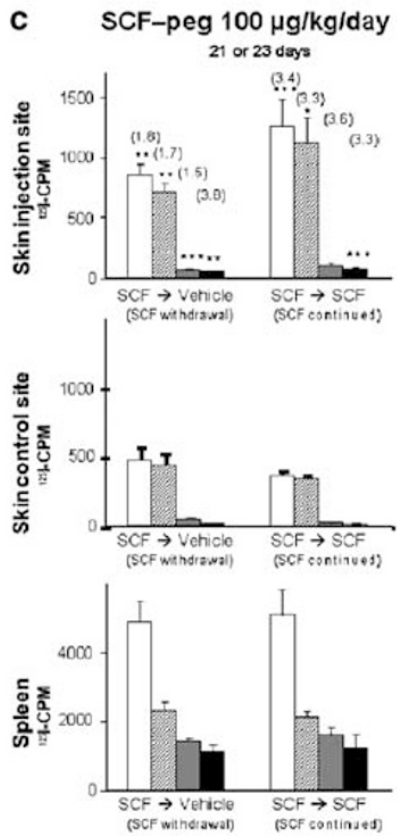

of radio-labeled fibrinogen was measured at the skin injection site, a skin control site that had not been subject to injection, and the spleen in mice treated with $\operatorname{rrSCF}^{164}$ (30 or $100 \mu \mathrm{g} / \mathrm{kg} /$ day for 21 or 23 days) and with rrSCF $^{164}$-peg (30 or $100 \mu \mathrm{g} / \mathrm{kg} /$ day for 23 or 92 days) (Figure $4 a-c)$.

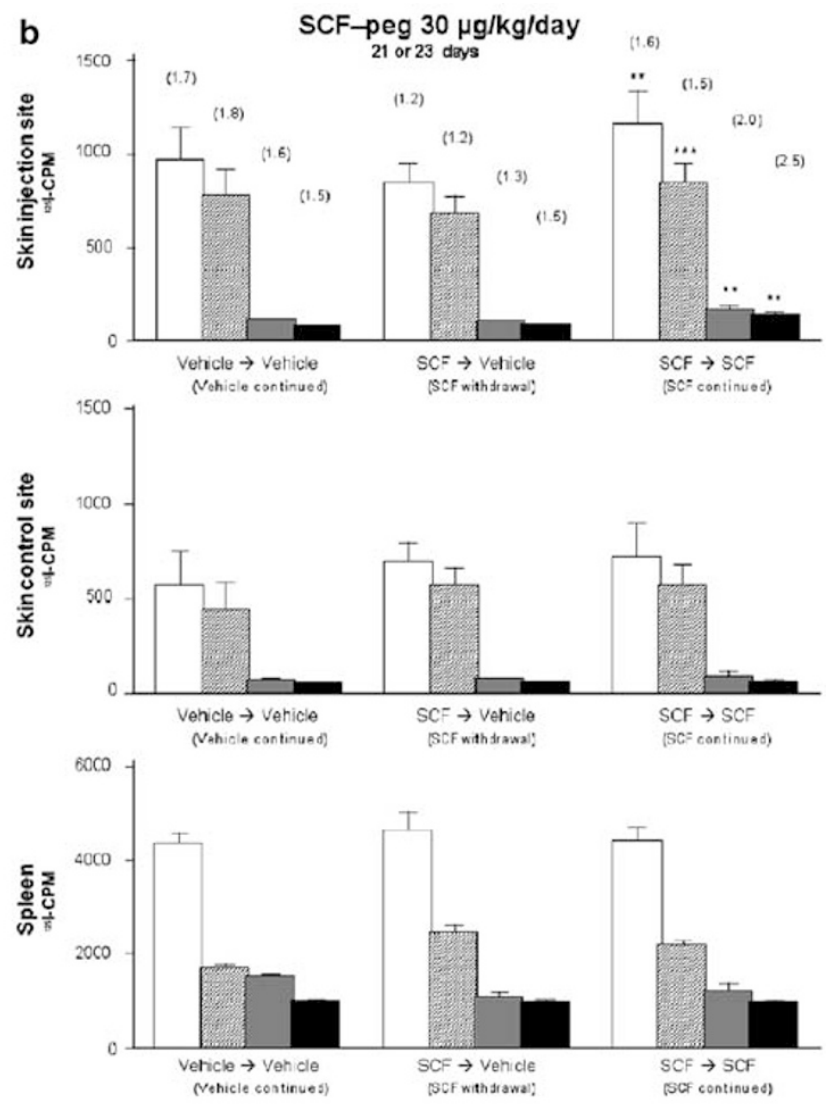

SCF-peg $100 \mu \mathrm{g} / \mathrm{kg} / \mathrm{day}$
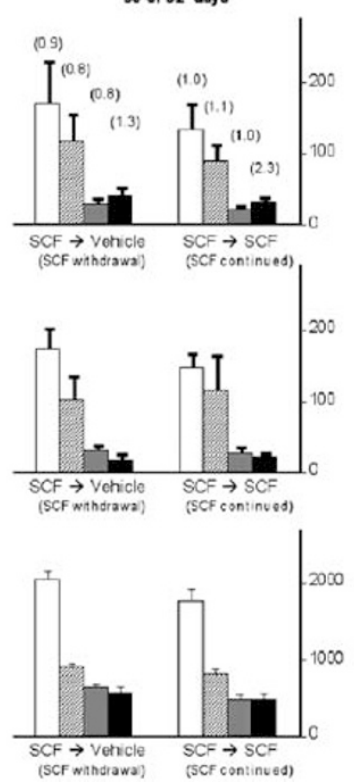
In all treatment groups except $\operatorname{rrSCF}^{164}$ at 30 $\mu \mathrm{g} / \mathrm{kg} /$ day for 21 days, values for crosslinked (urea insoluble) ${ }^{125}$ I-fibrin, and in many instances other ${ }^{125}$ I-fibrinogen-derived species, were higher in the skin sites that had been injected with SCF (skin injection sites) than in skin sites in the same mice that had not been directly injected with SCF (ie, skin control sites) (Figure 4a-c). In some instances, these differences achieved statistical significance. However, there were no statistically significant differences in the values for mice in the SCF continued vs the SCF withdrawal groups, whether one considers skin sites directly injected with SCF, control skin sites not injected with SCF, or the spleen (Figure $4 \mathrm{a}-\mathrm{C}$ ). This was true even for the groups in which the most striking changes in skin MC numbers occurred upon administration and then withdrawal of SCF, that is, those mice treated with $\mathrm{rrSCF}^{164}$-peg at $100 \mu \mathrm{g} / \mathrm{kg} /$ day for 21 or 90 days (Figure 4c).

In one set of experiments, we included a group of mice that was treated with vehicle alone ('vehicle continued' group in Figure 4b) instead of rrSCF$^{164}$ peg at $30 \mu \mathrm{g} / \mathrm{kg} /$ day for 21 ('SCF withdrawal' group) or 23 ('SCF continued' group) days (Figure 4b). Such vehicle-injected mice exhibited values for ${ }^{125} \mathrm{I}$-fibrin and other ${ }^{125}$ I-fibrinogen-derived species, in skin injection sites, control skin sites and spleen, that were statistically indistinguishable from those in the SCF continued or SCF withdrawal groups. In the SCF continued group, values for ${ }^{125} \mathrm{I}$-fibrin and other ${ }^{125}$ I-fibrinogen-derived species in skin injection sites were significantly higher than those in the corresponding control skin sites (Figure 4b). However, none of the values in the SCF continued group was significant when compared to the corresponding data for the SCF withdrawal or vehicle-treated groups.

We think that the simplest interpretation of all of our results is that the presence of a greatly expanded population of cutaneous MCs in SCF-treated mice may result in slightly enhanced local cutaneous vascular permeability, but that the rapid reduction of such populations of cutaneous MCs by apoptosis upon the withdrawal of SCF treatment results in no significant further enhancement of this effect.

\section{Effect of Chronic Treatment with SCF, or SCF Withdrawal, on Cutaneous Responses to Histamine or IgE and Antigen}

In one experiment, we attempted to elicit IgEdependent passive cutaneous anaphylaxis reactions in mice that had been treated with $\mathrm{rrSCF}^{164}$-peg at $30 \mu \mathrm{g} / \mathrm{kg} /$ day or with vehicle alone for 21 days, and in mice that were left untreated for 21 days. IgE antiDNP was injected into the skin at SCF injection sites $6 \mathrm{~h}$ after the injection of SCF or vehicle on the day before the end of the experiment (ie, day 20 of SCF or vehicle injection) and DNP-HSA was injected i.v. the next day, $24 \mathrm{~h}$ after the mice received their last injection of SCF or vehicle. Although injection of IgE and antigen resulted in a significant enhancement of vascular permeability in the SCF injection sites compared to sites in control mice injected with vehicle rather than IgE before antigen challenge, the values were significantly lower than those in mice that had been injected repeatedly at these sites with vehicle rather than SCF (total cpm: $2112 \pm 376$ vs $4734 \pm 537$ per biopsy, urea insoluble cpm: $714 \pm 121$ vs $1612 \pm 241$, respectively, $P<0.05$ ). This finding is consistent with our previous observation that mice treated chronically with $\mathrm{rrSCF}^{164}$ can exhibit both markedly increased numbers of tissue MCs and, paradoxically, reduced pathological consequences of systemic IgE-dependent reactions. ${ }^{14}$

rrSCF $^{164}$-peg can induce MC degranulation upon acute injection into the skin of normal mice. ${ }^{12}$ Therefore, it is possible that repeated injections of rrSCF ${ }^{164}$-peg can result in such sites exhibiting tachyphylaxis to the effects of mast cell mediators. To test this hypothesis, we injected histamine or vehicle alone intradermally into the skin injection sites or skin control sites of mice that had been injected with $\mathrm{rrSCF}^{164}$-peg at $100 \mu \mathrm{g} / \mathrm{kg} /$ day for 21 days (in the 'SCF withdrawal' group) or 23 days, (in the 'SCF continued' group), or with vehicle alone. As shown in Figure 5, we found that histamine induced significantly more enhancement of vascular permeability, as assessed by quantification of ${ }^{125}$ I-fibrinogen-derived species, than did vehicle, whether one evaluated the responsiveness of skin injection sites or skin control sites in the SCF continued, SCF withdrawal or vehicle continued groups. However, many of the ${ }^{125} \mathrm{I}-\mathrm{cpm}$ values in the histamine injections sites were slightly lower in the SCF continued or the SCF withdrawal groups than in the vehicle continued group. These results are consistent with the possibility that some tachyphylaxis to histamine can occur at cutaneous sites of mice that have been chronically injected with rrSCF $^{164}$-peg.

\section{Discussion}

The dermis of the mouse ordinarily is extremely sensitive to the proinflammatory effects of MC activation. In a previous report, we found that the induction of minimal degranulation of skin MCs (10 and $28 \%$ of MCs exhibiting morphological evidence of extensive or moderate degranulation, respectively) was sufficient to induce near-maximal levels of tissue swelling, as well as significant deposition of ${ }^{125}$ I-fibrin. ${ }^{12}$ Increasing levels of dermal MC activation resulted in progressively increasing amounts of local ${ }^{125}$ I-fibrin deposition. ${ }^{12}$ In the prior study, MC degranulation was induced in otherwise normal mice by the acute intradermal injection of rrSCF; thus, these mice had normal, or 'baseline', levels of dermal MCs. ${ }^{12}$ 

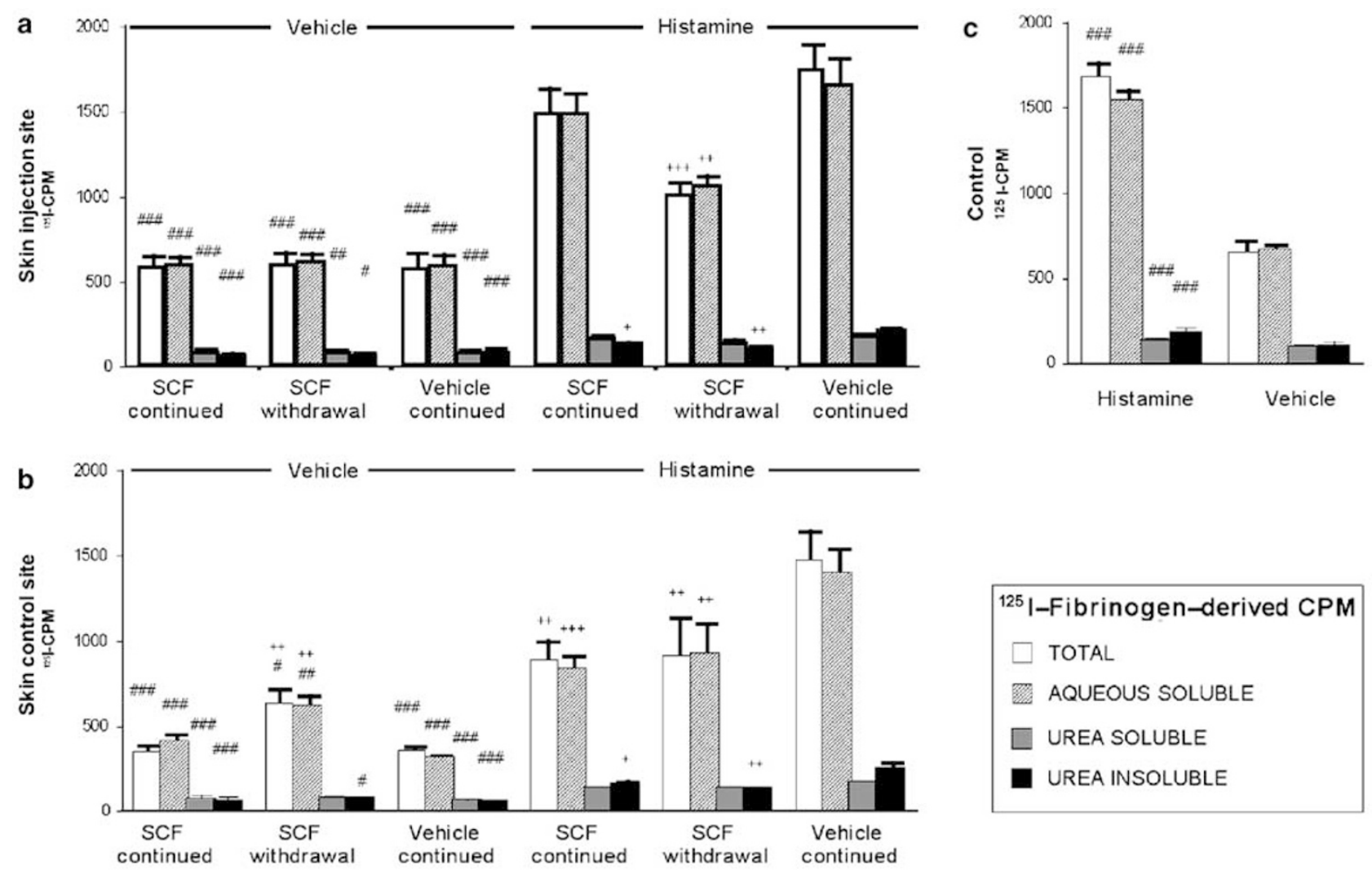

Figure 5 Reduced histamine-induced enhancement of vascular permeability at SCF cutaneous injection sites and control skin sites in mice that have been chronically treated with SCF. ${ }^{125}$ I-species in skin injection (a) and skin control (non-injected) sites (b) of C57BL/6mice ( $n=5 /$ group) injected with $\mathrm{rrSCF}^{164}$-peg at $100 \mu \mathrm{g} / \mathrm{kg} /$ day for 23 days ('SCF continued') or for 21 days followed by a 2 -day treatment with vehicle ('SCF withdrawal') to induce MC apoptosis, or of mice injected with vehicle for 23 days ('vehicle continued'). On day 23, mice from all treatment groups as well as untreated control mice (Control, c) received intradermal injections of histamine (2 $\mu \mathrm{g}$ in $20 \mu \mathrm{l}$ ) or vehicle alone and the amount and pattern of extractability of ${ }^{125} \mathrm{I}$-cpm were determined $2 \mathrm{~h}$ later. Unpaired two-tailed Student's $t$-test: ${ }^{\#} P<0.05,{ }^{\#} P<0.01,{ }^{\# \# \# P} P<0.005$ for histamine $v s$ vehicle; ${ }^{+} P<0.05,{ }^{++} \mathrm{p}<0.01,{ }^{+++} P<0.005$ for SCF withdrawal or SCF continued vs vehicle continued. At the time of killing, the ${ }^{125} \mathrm{I}-\mathrm{CPM}$ in $50 \mu \mathrm{l}$ of serum of histamine-injected mice as compared to vehicle-injected mice were $26730 \pm 5579$ vs $40216 \pm 1962$ (SCF withdrawal), $40247 \pm 1456$ vs $48734 \pm 1966$ (SCF continued) and $41979 \pm 2794$ vs $55575 \pm 1980$ (vehicle continued), respectively.

In the present study, withdrawal of chronic treatment with rrSCF resulted in the loss, by apoptosis, of a population of dermal MCs that was, depending on the rrSCF treatment protocol examined, from 7 to 65 times greater than that present normally in the dermis. Yet this marked reduction in dermal MC populations after cessation of rrSCF treatment in rrSCF-treated mice occurred with little or no local enhancement of dermal vascular permeability over that detected in corresponding sites in mice that remained on treatment with rrSCF, as assessed by the ${ }^{125}$ I-fibrin deposition assay, nor did it induce significant local infiltration of circulating leukocytes (Iemura et $a l^{4}$ and histological observations from this study, not shown).

In contrast to the results obtained at sites of massive MC apoptosis, the IgE-dependent activation of the expanded populations of dermal MCs at the sites of chronic injection of rrSCF induced significant local augmentation of ${ }^{125}$ I-fibrin deposition. In addition to demonstrating that MCs in mice chronically treated with rrSCF are capable of producing proinflammatory mediators upon appropriate IgEand antigen-dependent activation, this finding also showed that the local vasculature at sites of chronic treatment with $\mathrm{rrSCF}$ retained responsiveness to MC-derived mediators of enhanced vascular permeability. On the other hand, the induction of IgEdependent passive cutaneous anaphylaxis induced significantly greater levels of ${ }^{125}$ I-fibrin deposition in mice chronically injected with vehicle than in those chronically treated with rrSCF, even though the latter mice contained much higher numbers of dermal MCs. Moreover, responsiveness to histamine, as judged by the ${ }^{125}$ I-fibrin deposition assay, was also slightly reduced in rrSCF-treated as opposed to vehicle-treated mice.

We cannot rule out the possibility that tachyphylaxis, induced by chronic, presumably low level, extracellular release of biogenic amines from MCs, may have contributed to the low levels of vascular permeability at sites of rrSCF treatment. At least two mechanisms theoretically could have contributed to the occurrence of low levels of histamine release at 
such sites. In the 'SCF withdrawal' group, some histamine and serotonin may have been released extracellularly from MCs undergoing apoptosis upon withdrawal of SCF. In the 'SCF continued' group, injections of SCF might have induced c-kitdependent degranulation and release of biogenic amines from viable MCs. However, it bears emphasis that mechanisms other than (or, in addition to) tachyphylaxis to biogenic amines certainly may have contributed to the relatively low levels of vascular permeability and/or reduced responsiveness to injected histamine that were detected at sites of chronic injection with SCF.

Using a very different model system, Tokita and Yamamoto $^{15}$ recently reported that, upon intradermal injection into the skin of guinea-pigs, necrotic HL-60 cells enhanced local extravasation of plasma whereas apoptotic HL-60 cells had little or no effect. In the present study, we investigated the effects, on local vascular permeability (as assessed by ${ }^{125} \mathrm{I}$ fibrinogen extravasation and ${ }^{125}$ I-fibrin deposition), of the induction of apoptosis in native dermal MC populations whose numbers had been greatly expanded by the repetitive injection of the MC growth/ survival factor, SCF. Our findings clearly show that the very large population of dermal MCs induced to develop by repetitive treatment with rrSCF can be eliminated by apoptosis under conditions that result in little or no detectable local enhancement of local vascular permeability. Our results thus provide dramatic evidence that apoptosis can indeed result in the removal of even extremely large endogenous populations of highly 'proinflammatory' cells without the concomitant induction of a significant inflammatory response.

\section{Acknowledgements}

We thank S Fish for excellent technical assistance. This work was supported by the United States Public Health Science Grants CA/AI-72074, AI/GM23990, 5 U19 AI41995 (Project 1) and HL67674 (to SJ Galli) as well as a grant of the Deutsche Forschungsgemeinschaft (M Maurer). We thank F-T Liu and D Katz for the monoclonal IgE and Amgen, Inc., for the rrSCF and rrSCF-peg used in these studies. S Galli has performed research supported by Amgen, Inc., and has consulted Amgen, Inc., under terms that are in accordance with the conflict of interest policies of Beth Israel Deaconess Medical Center and Stanford University.

\section{References}

1 Voll RE, Herrmann M, Roth EA, et al. Immunosupressive effects of apoptotic cells. Nature 1997;390: 350-351.

2 Wyllie AH. Apoptosis: an overview. Br Med Bull 1997;53:451-465.

3 Savill J. Phagocytic docking without shocking. Nature 1998;392:442-443.

4 Iemura A, Tsai M, Ando A, et al. The c-kit ligand, stem cell factor, promotes mast cell survival by suppressing apoptosis. Am J Pathol 1994;144:321-328.

5 Galli SJ, Metcalfe DD, Dvorak AM. Basophils and mast cells and their disorders. In: Beutler E, Lichtman MA, Coller BS, Kipps TJ, Seligsohn U (eds). Williams Hematology, 6th edn. McGraw-Hill: New York, 2001, pp 801-815.

6 Metcalfe DD, Baram D, Mekori YA. Mast cells. Physiol Rev 1997;77:1033-1079.

7 Kaliner M, Lemanske R. Inflammatory responses to mast cell granules. Fed Proc 1984;43:2846-2851.

8 Tsai M, Shih L-S, Newlands GFJ, et al. The rat c-kit ligand, stem cell factor, induces the development of connective tissue-type and mucosal mast cells in vivo. Analysis by anatomical distribution, histochemistry and protease phenotype. J Exp Med 1991;174:125-131.

9 Mekori YA, Dvorak HF, Galli SJ. ${ }^{125}$ I-Fibrin deposition in contact sensitivity reactions in the mouse. Sensitivity of the assay for quantitating reactions after active or passive sensitization. J Immunol 1986;136:2018-2025.

10 Wershil BK, Mekori YA, Murakami T, et al. ${ }^{125} \mathrm{I}-F i b r i n$ deposition in IgE-dependent immediate hypersensitivity reactions in mouse skin. Demonstration of the role of mast cells using genetically mast cell-deficient mice locally reconstituted with cultured mast cells. J Immunol 1987;139:2605-2614.

11 Yano $\mathrm{H}$, Wershil BK, Arizono N, et al. Substance $\mathrm{P}$-induced augmentation of cutaneous vascular permeability and granulocyte infiltration in mice is mast cell dependent. J Clin Invest 1989;84:1276-1286.

12 Wershil BK, Tsai M, Geissler EN, et al. The rat c-kit ligand, stem cell factor, induces c-kit receptordependent mouse mast cell activation in vivo. Evidence that signaling through the c-kit receptor can induce expression of cellular function. J Exp Med 1992;175:245-255.

13 Wershil BK, Murakami T, Galli SJ. Mast cell-dependent amplification of an immunologically nonspecific inflammatory response: mast cells are required for the full expression of cutaneous acute inflammation of 12myristate 13-acetate. J Immunol 1988;140:2356-2360.

14 Liu FT, Bohn JW, Ferry EL, et al. Monoclonal dinitrophenyl-specific murine IgE antibody: preparation, isolation, and characterization. J Immunol 1980; 124:2728-2737.

15 Tokita K, Yamamoto T. Different role of neutrophils and monocytes during subcutaneous plasma extravasation. Lab Invest 2004;84:1174-1184. 